\section{Evaluation of neurodevelopment of preterm infants using Bayley III scale}

\section{Avaliação do neurodesenvolvimento em lactentes pré-termos usando a escala Bayley III}

Fernanda Veiga de Góes 1

Maria Dalva B. B. Méio 2 Rosane Reis de Mello 3

Denise Morsch 4

\section{Abstract}

Objectives: to assess cognitive, motor, and language development in preterm infants, and perinatal, neonatal and socioeconomic factors associated with abnormal development.

Methods: a cross-sectional study was carried out with 104 preterm infants (gestational ages $<33$ weeks) (17 - 30 months corrected ages) using the Bayley III Scale. Logistic regression analysis was performed and prevalence ratios calculated.

Results: the average language score (81.9) was low, while cognitive (93.7) and motor (91.1) scores were within normal values. There were deficiencies in receptive but not in expressive language. Male sex (OR 2.55 CI 1.01-6.44) and neonatal pneumonia (OR 33.85 CI 3.3-337.8) were associated with abnormal language scores. No factor was associated with abnormal cognitive scores; male gender indicated an increased risk of abnormal motor scores. The lack of a father was a risk factor for impaired motor development (PR: 2.96, CI: 5.6 - 1.55). There was no statistically significant difference in the development of small and appropriate for gestational age children.

Conclusions: the Bayley III Scale was useful for assessing language and cognition separately, discriminating between receptive and expressive language. There was a high frequency of language deficiencies, especially in receptive language. Although motor and cognitive average scores were within the normal range, there was a high frequency of children with delayed development in these areas, especially motor development.

Key words Infant development, Intelligence tests, Infant, premature
1-3 Departament of Pediatrics. Instituto Fernandes Figueira (IFFFIOCRUZ). Av Rui Barbosa, 716. $4^{\circ}$ floor. Flamengo. Rio de Janeiro, RJ, Brazil. CEP: 22.250-020. E-mail: fernanda.veiga@terra.com.br 4 Pontifícia Universidade Católica do Rio de Janeiro. Rio de Janeiro, RJ, Brazil.

\section{Resumo}

Objetivos: avaliar o desenvolvimento motor, linguagem e cognitivo em prematuros e fatores perinatais, neonatais e socioeconômicos associados ao desenvolvimento anormal.

Métodos: estudo transversal: 104 recém-nascidos pré-termos (idade gestacional $<33$ semanas) foram avaliados (17 - 30 meses idade corrigida), utilizando a Escala Bayley III. Realizada análise de regressão logística e calculadas razões de prevalência.

Resultados: a média do escore de linguagem $(81,9)$ foi baixa, enquanto as dos escores cognitivo $(93,7)$ e motor $(91,1)$ estavam normais. Foram encontrados déficits na linguagem receptiva, não na expressiva. Sexo masculino (OR 2,55 IC 1,01-6,44) e pneumonia neonatal (OR 33,85 IC 3,3-337,8) foram associados com escores anormais de linguagem. Nenhum fator foi associado a pontuações cognitivas anormais; sexo masculino indicou risco aumentado de escores motores anormais. Ausência do pai foi risco para desenvolvimento motor (RP: 2,96 IC 5,6-1,55). Não houve diferença estatística entre o desenvolvimento de crianças pequenas e adequadas para idade gestacional.

Conclusões: a escala Bayley III foi vantajosa para avaliar linguagem e cognição separadamente, discriminando linguagem receptiva e expressiva. Houve uma elevada frequência de déficit de linguagem, especialmente receptiva. Embora os escores motor e cognitivo médios estivessem na faixa normal, houve uma alta frequência de atraso nestas áreas, principalmente a motora.

Palavras-chave Desenvolvimento infantil, Testes de inteligência, Prematuro 


\section{Introduction}

Neuropsychomotor development in infants born prematurely is of great concern to professionals who are involved in the care of these children. ${ }^{1}$ It is well known that infants born prematurely have developmental impairments, mainly within the group of extreme preterm infants. ${ }^{2-3}$

Previously, the majority of studies assessing the development of preterm infants have used the Bayley Scale (2nd edition), in which language is evaluated together with cognition (mental development index) and the fine and gross motor skills, which are part of the psychomotor development index. However, in the latest version of the scale ( $3^{\text {rd }}$ edition), language and cognition are assessed independently, allowing language delay to be identified separately from cognitive delay. Moreover, the scale also allows for discrimination between expressive and receptive language in addition to gross and fine motor skills.

The Bayley Scales of Infant and Toddler Developmental III (BSID III - 2006) is a relatively new scale for the evaluation of children. Although some international studies have been published using these scales, 4,5 there are still a few studies evaluating Brazilian children.6-10

Many perinatal and environmental factors have been linked to inadequate neurodevelopment among preterm infants. 1,2 The identification of development delays is important for intervention planning and parent counseling.4,6 The BSID III were chosen as the instrument of evaluation, as it permits a better assessment of overall and specific areas of development.

The aims of the present study were as follows: 1) to evaluate the cognitive, motor and language development of children born at a gestational age of less than 33 weeks at 17 to 30 months corrected age using the BSID III; 2) to evaluate gestational, perinatal and neonatal factors, along with socioeconomic factors and family histories, that may predict outcomes.

\section{Methods}

A cross-sectional study was conducted with a cohort of children born preterm between June 2005 and December 2008, and followed up by the Follow-up Clinic of the Department of Neonatology at the Fernandes Figueira Institute. These infants were born at gestational ages of less than 33 weeks. The infants were included in the cohort regardless of their birth weights.
This is a follow up clinic of a tertiary public hospital only for children born in this unit and who have been admitted to the Neonatal Intensive Care Unit (NICU); the children are followed up to the beginning of adolescence. The follow-up team is composed of pediatricians, a physiotherapist, an occupational therapist, a speech therapist, a psychologist, and a social worker.

Infants with congenital malformations and genetic syndromes, congenital infections confirmed by blood tests, fetal hydropsy and $\mathrm{Rh}$ isoimmunization with intrauterine transfusion were excluded from the initial cohort. In the present study, children were included if they completed a developmental assessment using the BSID III at a corrected age of between 17 and 30 months. Children with serious sensorial deficiencies (auditory or visual) or who could not perform the Scale tasks for motor or mental reasons were excluded.

Gestational histories, antenatal use of corticosteroids, birth conditions, anthropometric data at birth, neonatal histories, types of feeding, socioeconomic and family histories, clinical outcomes after discharge from the NICU, and Bayley III Scale scores were recorded.

Gestational age (GA) was obtained using the date of the mother's last menstrual period. If this information was unavailable, a gestational ultrasound (completed at up to 12 weeks of pregnancy) or the New Ballard scale11 was used, in that order. The classification of small for gestational age (SGA) and appropriate for gestational age (AGA) was based on $\mathrm{Z}$ scores for the weight for GA and sex. Newborns were considered to be SGA if their birth weight was lower than two standard deviations (SD) below the average, in accordance with the international consensus published by Lee $e t$ al. 12 using the data from Kramer et al.13 as a reference.

The following data in regard to the perinatal and therapeutic procedures that were performed during the infant's NICU stay were recorded: hyaline membrane disease, bronchopulmonary dysplasia (defined by the use of oxygen for a time greater than or equal to 28 days), 14 pneumonia, fifth minute APGAR score of less than 6, persistence of hemodynamically significant ductus arteriosus, abnormal ultrasound (presence of cysts, confirmed or suspected periventricular leukomalacia, any degree of intraventricular hemorrhage or other cerebral bleedings), intraventricular hemorrhage (according to Papile), 15 ventilation support, corticosteroid after birth and septicemia (positive 
blood cultures). Data on diet after discharge were collected (breastfeeding and/or formula). The following socioeconomic factors and family factors were recorded: per capita income, the presence of a paternal and maternal figure, maternal and paternal education in years, and the categorization of family type according to the Brazilian Institute of Geography and Statistics (IBGE) (i.e., a single family - defined as a group of individuals linked by direct relationships living in the same household unit, or a cohabitant family - consisting of at least two different families sharing the same house). ${ }^{16}$

The BSID III was used, whose composite score, according to the authors, ranges from 40-160, with a mean of 100. A score of between 85 and 115 is equivalent to one standard deviation below and above the mean score respectively. 17 Receptive and expressive language and fine and gross motor development scores were standardized to a mean age with an average of $10( \pm 3)$. This scale was administered by three qualified psychologists, who were blind to the clinical histories of the children; the test was performed in a separate room and the psychologists did not have access to the child's records. A reliability test between the psychologists (inter-rater) had been performed prior to the initiation of the study. The intra-class correlation coefficient (ICC) for the field of mental skills was 0.94 (CI 0.8-0.98) and 0.91 (CI 0.76-0.97) for motor skills.

The statistical program Epi Info version 3.5.1 was used for data analysis. The average cognitive, language and motor scores; the mean of the absolute values for receptive and expressive language; and fine and gross motor development were calculated. The ANOVA parametric test was used to test for differences in means. Three main outcomes were considered: cognitive, language and motor development. Children were considered to have normal development when their scores in each different area were equal to or greater than 85 ; scores below 85 were considered abnormal. The chi square test was used to compare proportions of normal and abnormal scores, with a significance level of 0.05 . A logistic regression analysis was performed to evaluate the presence of perinatal factors associated with abnormal development. Variables were included in the model if they were associated with each of the outcomes in the univariate analysis $(p \leq 0.20)$; classification of SGA or AGA was also included, as a factor of interest. Social and family factors were considered to be confounders. The stepwise method was used to estimate the best model. The prevalence ratio was calculated for perinatal, neonatal and socioeconomic factors and the cognitive, language and motor scores. The present study was approved by the Research with Human Beings Ethics Committee at the Institution (0080.0.008.000-CAAE - 10); the parents or caregivers of the children provided informed consent for their children to participate.

\section{Results}

Between April 2005 and December 2008, 328 children were born in the maternity unit at the Fernandes Figueira Institute; eight were transferred to other units, 41 died in the neonatal period and 101 were excluded from the cohort ( 89 with congenital malformations and/or genetic syndromes, 4 with fetal hydropsy, 3 with $\mathrm{Rh}$ isoimmuzation needing intrauterine transfusion).

The potential cohort was 178 newborns. Of these, 4 died after discharge, the family of 7 refused to participate in the study, and 60 were lost to follow up. Of the 107 who were followed, one was excluded for blindness and two with cerebral palsy, as they were unable to perform the test.

We evaluated 104 children with an average corrected age of 23 months at the time that the BSID III was administered, between March 2007 and March 2011, the corrected age ranging from 17 to 30 months. Of these, $45.2 \%$ were male, and $21.2 \%$ were SGA with a mean gestational age at birth of 29 weeks and 5 days. The duration of stay in the NICU ranged between 16 and 161 days, with a mean of 55.3 days (SD 31.5) (Tables 1 and 2).

We found abnormal ultrasound in 22 children (21.2\%), of whom $20(19.6 \%)$ had intraventricular hemorrhage: $80 \%$ with grade I and II, three with grade III and one grade IV. The number of children with sepsis was $12(11.5 \%)$, with the same number for pneumonia; only three patients had both diagnoses.

Most infants $(\mathrm{n}=64,61.5 \%)$ breastfed for a median of 4 months, and 40 infants (38.5\%) received only milk formula after discharge from the NICU; only $10 / 64$ children who breastfed $(9.6 \%)$ received exclusive breastfeeding for a median time of 3 months. Readmissions to the hospital were 33/104 $(31.7 \%)$ in the first year of life and 13/104 (12.5\%) in the second year of life.

The mean of maternal and paternal years of education was 9 , and the mean per capita income was near the minimum wage. The presence of a mother (96.2\%) and father (90.4\%) was common in the families studied. Children in the study population frequently lived with both parents $(78.8 \%)$, and 
Table 1

Demographic characteristics and perinatal factors among preterm infants with gestational ages of below 33 weeks ( $n=104)$, RJ, 2005-2008.

\section{Maternal characteristic}

Maternal age (years) - mean (SD)

Cesarean delivery - $\mathrm{n}(\%)$

$26.7(7.7)$

Gestational age (weeks and

67 (64.4)

Smokera - n (\%)

29 w 5 d $(2$ w 1d)

Alcoholb - n (\%)

$11(11.0)$

$20(20.8)$

Diabetes - n (\%)

$6(5.8)$

Maternal hypertensionc- n (\%)

39 (37.9)

Infants' characteristics

Birth weight (g) - mean (SD)

1210.6 (352.0)

Length at birth $(\mathrm{cm})$ - mean (SD)

$37.3(4.3)$

Head circumference at birth (cm) - mean (SD)

$26.9(2.6)$

Male - n (\%)

47 (45.2)

SGA - n (\%)

$22(21.2)$

APGAR fifth minute $<6-\mathrm{n}(\%)$

5 (4.8)

Resuscitation* - n (\%)

$47(45.2)$

$\mathrm{SGA}=$ Small for Gestational Age; *Resuscitation= need for positive pressure ventilation, external cardiac massage or endotracheal intubation in the delivery room; a Smoker $n$ total=100; b Alcohol $n$ total $=96$; $c$ Maternal hypertension $n$ total $=103$.

\section{Table 2}

Frequencies of neonatal complications and procedures among preterm infants with gestational ages of less than 33 weeks, ( $n=104)$, RJ, 2005-2008.

\section{Complications and procedures}

\begin{tabular}{lc} 
Hyaline membrane diseases- $\mathrm{n}(\%)$ & $82(78.8)$ \\
Surfactant - $\mathrm{n}(\%)$ & $58(55.8)$ \\
Ventilatory assistance - $\mathrm{n}(\%)$ & $63(60.6)$ \\
Neonatal pneumonia - $\mathrm{n}(\%)$ & $12(11.5)$ \\
Sepsis - $\mathrm{n}(\%)$ & $12(11.5)$ \\
Abnormal transfontanelle ultrasonography - $\mathrm{n}(\%)$ & $22(21.2)$ \\
Intracranial hemorrhagea - $\mathrm{n}(\%)$ & $20(19.6)$ \\
Persistence of the ductus arteriosus - $\mathrm{n}(\%)$ & $50(48.1)$ \\
Bronchopulmonary dysplasia - $\mathrm{n}(\%)$ & $27(26)$ \\
Total parenteral nutritionb - $\mathrm{n}(\%)$ & $95(94.1)$ \\
Hours in $\mathrm{O}_{2}$ - mean (SD) & $500.8(685.9)$ \\
Days to recovery of birth weight - mean (SD) & $16.1(7.2)$ \\
Percentage of weight lost - mean (SD) & $13.4(5.6)$ \\
Duration of NICU stay- mean (SD) & $55.3(31.5)$ \\
\hline NICU = Neonatal Intensive Care Unit; a Intracranial hemorrhage $\mathrm{n}$ total = 102; b Total parenteral nutrition \\
$\mathrm{n}$ total = 101.
\end{tabular}


the dominant family type was the single type (75\%). In this population, 39 mothers $(37.5 \%)$ and 36 fathers $(40.4 \%)$ had 12 or more years of schooling.

Average scores were within the normal ranges for both cognitive $(93.7 \pm 11.3)$ and motor development $(91.1 \pm 11.6)$. However, average language scores $(81.9 \pm 13.0)$ were below normal. The proportion of children with an abnormal score was $50 \%$ for language (52/104), 25\% for motor skills (26/104), and $13 \%$ for cognitive skills (13/104).

The average expressive language score was 7.9 $( \pm 2.5)$, while the average receptive language score was $6.7( \pm 2.3)$. For the motor components, the means were as follows: $8.6( \pm 2.0)$ for fine motor skills and $8.4( \pm 2.3)$ for gross motor skills.

The mean motor and cognitive scores were normal, while the mean language score was below normal. Only children with neonatal pneumonia had significantly lower language scores (70.9 \pm 9.1 , $p=0.001$ ). There were no significant differences in mean scores in any area between the SGA and AGA children.

After analysis of the relationship between the abnormal cognitive scores, perinatal, neonatal and socioeconomic factors, neonatal pneumonia and fifth minute APGAR scores of less than 6 were the only risk factors that were identified. In relation to language, abnormal scores were associated with the male sex, fifth minute APGAR scores of less than 6 and neonatal pneumonia, whereas living with parents was a protective factor. As for the motor score, male sex was the only risk factor for abnormal scores (PR: 2.15, CI: 1.04-4.42).

When socioeconomic factors were analyzed, paternal and maternal education, per capita income and the presence of a mother did not affect the mean scores for any of the outcomes. The absence of a father figure increased the risk for abnormal motor scores (PR: 2.96, CI: 5.6-1.55).

In the multivariate analysis, no factor was associated with abnormal cognitive scores. Regarding to the language scores, male sex and neonatal pneumonia were the only risk factors for abnormal development, and a single family was found to be a protective factor for normal language development (Table 3). The risk of abnormal motor scores was only significant in males (Table 4).

Table 3

Results of logistic regression for impairment in language domain Bayley III Scale: adjusted odds ratio (OR) and 95\% confidence interval $(\mathrm{Cl})$ for other variables.

\begin{tabular}{lccc}
\hline & Adjusted OR & Cl95\% & p \\
\hline Language score* & & & $3.3-337.8$ \\
$\quad$ Neonatal pneumonia & 33.85 & $1.01-6.44$ & 0.003 \\
Male sex & 2.55 & $0.06-0.86$ & 0.047 \\
Family type & 0.23 & 0.029 \\
\hline
\end{tabular}

*Adjusted for asphyxia, hyaline membrane diseases, ventilatory assistance. confidence interval $(\mathrm{Cl})$ for other variables.

\begin{tabular}{lccc} 
& Adjusted OR & CI95\% & $p$ \\
\hline $\begin{array}{l}\text { Motor Score* } \\
\text { Male }\end{array}$ & 2.99 & $1.08-8.21$ & 0.03
\end{tabular}

*Adjusted for small gestational age, cohabitation of parents, bronchopulmonary dysplasia, pneumonia and family type. 


\section{Discussion}

The present study found worse outcomes in regard to language development. Half of the infants who were studied had abnormal language scores, a fourth of them had abnormal motor scores, and $13 \%$ had abnormal cognitive scores, although the mean cognitive and motor scores were within the normal ranges.

The BSID III has been used in recent studies to assess preterm development. The first study using this scale for development assessment, published in 2010 , compared preterm infants born prior to 28 weeks or with $\mathrm{BW}<1000 \mathrm{~g}$ with a control group of infants born at term and with appropriate birth weights at a corrected age of 2 years old. The mean score for all of the premature children was within the normal range for the scale, although, when compared with the control group, the population scores of the preterm children were significantly lower. The authors reported a smaller proportion of abnormal BSID III scores: $10 \%$ for cognitive scores, $8 \%$ for motor scores and $15 \%$ for language scores. These results are better than those of the present study in relation to language and motor scores, in which the proportions of abnormal scores were $50 \%$ and $25 \%$, respectively. However, the proportions of abnormal cognitive scores were similar: $10 \%$ in the Australian population 18 and $13 \%$ in ours.

The higher frequency of language delay found in our cohort, compared to the Australian study may reflect the lower levels of education of the mothers in our population. In the Australian cohort of Anderson et al. $1866 \%$ of the mothers had at least 12 years of schooling, while in our population the mean was 9 years. This may partially explain the lack of stimulation of these Brazilian children at home. It is well known that better educated mothers and the family's level of knowledge influence the care of children, favoring greater stimulation.

Fernandes et al. 6 evaluated 58 very low birth weight Brazilian children. The authors also found greater language delay $(29.3 \%)$, with a low proportion of abnormal motor and cognitive scores - $6.9 \%$ for both outcomes. As in the present study, a higher proportion of abnormality in language development was found, although to a lesser degree than in the present study. However, Fernandes et al. ${ }^{6}$ did not report on the subscales for language (receptive and expressive) and motor (fine and gross) skills. The present study found greater receptive language delay and no difference in fine and gross motor skills. Another study, by Eickmann et al., ${ }^{9}$ using the BSID III to assess a Brazilian population of 45 preterm and 90 full term newborns at chronological ages of 6 and
12 months found a statistically significant difference only in expressive language. However, the gestational age of the preterm group varied from 25 to 36 weeks, with only three children having a gestational age less than or equal to 30 weeks. Nevertheless, they found impairment in language skills. In our population, the deficiency was in receptive language, whereas in theirs it was in expressive language. In both Fernandes et al. ${ }^{6}$ and Eickmann et al. ${ }^{9}$ children born at greater gestational ages were included, while, in the present study, all the 104 children were born with a gestational age of less than 33 weeks, i.e. less mature at birth. This may explain the higher proportion of developmental delays found in our population in all areas. In relation to the differences in the predominance of expressive and receptive language impairment between Eickmann et al. ${ }^{9}$ and the present study, it could be hypothesized that the age at which the children were evaluated explain these differences, since our population was older (17 - 30 months) at the time of evaluation compared with theirs (6 - 12 months), which is probably reflected in different language abilities.

The EPICure Study Group (2000) reported mental development and psychological development scores of $84 \pm 12$ and $87 \pm 13$, respectively, at the age of 30 months. ${ }^{3}$ In a Dutch cohort 19 of preterm children below 33 weeks gestational age, $40 \%$ of infants had mental or psychomotor delay at 18 and 24 months of age. In both cohorts, the BSID II was used to assess development and a higher prevalence of cognitive deficits in preterm children was reported.

One of the advantages of the BSID III is its ability to assess language and cognition separately. These had previously been measured using the mental development index (MDI) on the BSID II. The BSID III is also able to discriminate between receptive and expressive language. The same is true for the assessment of motor skills, which had been previously called the psychomotor development index (PDI) on the BSID II. On the BSID III, motor domains are separated into fine and gross motor development. A possible explanation for MDI scores below the normal range on the BSID II is that language is evaluated together with cognition, whereas language is separated on the BSID III, thereby providing evidence of language impairment.

The results showed that the gross and fine motor scores were within the normal ranges. However, the raw score for receptive language was lower than expected. The literature is inconsistent in respect to whether there is a deficiency in either expressive or receptive language or whether there is a deficiency 
in both. $5,20-22$ Wild et al. ${ }^{20}$ studied 65 pairs of children born with gestational age lower or equal to 32 weeks, from two different income populations, between 15 and 30 months. They found similar raw scores for receptive and expressive language in both groups, but the means were lower in the poorer group.

Newborns begin the process of acquiring and developing oral language at birth. Indeed, many of the neural structures that are required for this process are already present in newborns and are gradually developed and enhanced by experiences, social interactions and communication. A possible hypothesis for the finding of low receptive language scores and expressive language scores that were within the expected range could be that in normal language development, comprehension precedes language expression, 21,22 and the population in this study was evaluated with a mean of 23 months corrected age. Expressive language may therefore still fit within a normal pattern, necessitating further testing at older ages to confirm the findings of this study. These results support the need for future studies on language development in preterm children.

Several publications identify male sex as a risk factor for developmental delay.6,23-24 The mechanisms underlying this susceptibility remain unknown. In a study conducted in the Netherlands, male sex was noted to be a risk factor for delayed motor performance at the age of 2 to 3 years among children born at gestational ages of less than 33 weeks. The data from this study are consistent with those obtained in our study. 23 Hintz et al. 24 found that male preterm children had increased constitutional risks for adverse outcomes regardless of perinatal, neonatal or early infancy diseases and posited that these differences were related to biological factors, such as fetal central brain development, hormonal factors or genetic evolution of the different sexes.

In respect to neonatal pneumonia, we did not find any data in the literature confirming the association of the presence of pneumonia with language delay. These findings may be explained by the correlation between neonatal pneumonia and other risk factors, such as sepsis and bronchopulmonary dysplasia.

Surprisingly, peri-intraventricular hemorrhage was not associated with abnormal scores in any of the development domains, different from the findings reported in the literature. 8 The explanation for this lack of effect may be that in our population there were very few newborns with grade III or IV peri- intraventricular hemorrhage (4/104 children).

Development is a multifaceted process and abnormalities cannot be explained by any single aggravating or protective factor. The family unit plays a fundamental role in a child's development, helping to minimize the effects of perinatal damage, primarily through the participation of parents in the care of the child.20,25 In the present study, the type of family, i.e., a single family, was noted to be a protective factor for language development. A study evaluating genetic and environmental influences on pairs of twins of the same sex showed that early environmental factors modified verbal and nonverbal cognitive development at 2 years of age among children born at a gestational age of under 32 weeks. 26

There was no association between the absence of a father and cognitive scores, although the absence of a father was found to be a risk factor for abnormal motor development. A possible explanation for this result may be the importance of the interaction between parents and children, making the home environment conducive to motor stimulation. Paternal involvement is important in the early development of infants. It has been shown that paternal involvement in the care of their children improves cognitive performance. 27

There were no differences in neurodevelopment between the SGA and AGA groups. Similar results were found by Procianoy et al.,28 comparing the neurodevelopment of 96 very low birth weights preterm children using the BSID II at corrected ages of 8,12 and 24 months. The PDI and MDI were similar in both groups up to a corrected age of 24 months. Different results were found by De Jesus et al., 29 who reported neurodevelopmental impairment in SGA extreme preterm children at a corrected age of 18-22 months using the BSID III. Both the mean cognitive score (less than 80 ) and the mean language score (less than 70) were lower in the SGA group compared to the AGA group. But the authors studied only very extreme preterm born children with a gestational age of 27 weeks or lower. They also used a less restrictive cut off point to define SGA $-10^{\text {th }}$ percentile on the reference growth chart, which creates difficulties when making comparisons.

One of the limitations of the present study is that it used a single center sample, thereby reducing its generalizability. In addition, subjects were recruited from a cohort of children who were being followed up during the study period, thus characterizing a convenience sample and limiting the power of our analysis. Another limitation was the loss in the follow up, although the groups were compared by 
socioeconomic, gestational and neonatal factors and there were no differences between those included in the study and the lost population. However, it was possible to assess 104 children born preterm with less than 33 weeks gestational age, despite belonging to a low income population. A further limitation is that there were no formal assessments of the home, socio-economic and family environments of the population under study. However, some social and family categories were studied, by way of information provided by the parents. There may be a limitation in the evaluation of the association between the variables studied and the outcomes.

In conclusion, a high frequency of delay in language development was found. Although the average cognitive and motor scores were within the normal ranges, a significant percentage of premature infants were delayed in these areas. In the present study, the use of the BSID III enabled better evaluation of the three principal domains of development.
The language assessment showed that receptive language capacity was lower than the average expected for this age group, although no abnormalities were observed in expressive language, which may be indicative of future difficulties in school, reinforcing the importance of the early identification of language difficulties prior to the acquisition of literacy. Family status influenced the children's development, whereas the presence of the father improved motor performance, and language scores were better within structured families.

\section{Acknowledgements}

We are grateful to Fátima Junqueira, Ana Beatriz Reis and Juliana Delamonica, the psychologists who performed the Bayley III Scale evaluations, and to Maria Elizabeth Lopes Moreira, the neonatologist who was responsible for the coordination of the project.

\section{References}

1. Stephens BE, Vohr BR. Neurodevelopmental Outcome of the Premature Infant. Pediatric clinics of North America 2009; 56: 631-46.

2. Hintz SR, Kendrick DE, Vohr BR, Poole WK, Higgins RD for National Institute of Child Health and Human Development Neonatal Research Network. Changes in Neurodevelopmental outcomes at 18 to 22 months corrected age among infants of less than 25 weeks' gestational age born in 1993-1999. Pediatrics. 2005; 115: 164551

3. Wood NS, Marlow N, Costeloe K, Gibson AT, Wilkinson AR. Neurologic and developmental disability after extremely preterm birth for the EPICure Study Group. N Eng J Med. 2000; 343: 378-84.

4. Serenius F, Källén K, Blennow M, Ewald U, Fellman V, Holmström G, Lindberg E, Lundqvist P, Marsál K, Norman M, Olhager E, Stigson L, Stjernqvist K, Vollmer B, Strömberg $\mathrm{B}$; for the EXPRESS group. Neurodevelopmental outcome in extremely preterm infant at 2.5 years after active perinatal care in Sweden. JAMA. 2013; 309 (17): $1810-20$

5. Greene MM, Patra K, Nelson MN, Silvestri JM. Evaluating preterm infants with the Bayley-III: patterns and correlates of development. Res Dev Disabil. 2012; 33 (6): 1948-56.

6. Fernandes LV, Goulart AL, dos Santos AM, Guerra CC, Kopelman BI. Neurodevelopmental assessment of very low birth weight preterm infants at corrected age 18-24 moths by Bayley III scales. J Pediatr (Rio J). 2012; 88 (6): 471-8.

7. Toro-Ramos T. Preterm infant language developmental: a role for breast milk fatty acids. J Hum Growth Dev. 2013 23 (3): 270-5.

8. Guerra CC, Barros MCM, Goulart AL, Fernandes LV, Kopelman BI, dos Santos AMN. Premature infants with birth weights of $1500-1999 \mathrm{~g}$ exhibit considerable delays in several developmental areas. Acta Paediatr. 2014; 103: e1e6.

9. Eickmann SH, Malkes NFA, Lima MC. Psychomotor development of preterm infants aged 6 to 12 months. Med J (São Paulo). 2012; 130 (5): 299-306.

10. Viana TP, Andrade ISN, Lopes ANM. Desenvolvimento cognitivo e linguagem em prematuros. Audiol Commun Res. 2014; 19 (1): 1-6.

11. Ballard JL, Khoury JC, Wedig K, Wang L, Eilers- Ealsman BL, Lipp R. New Ballard score, expanded to include extremely premature infants. J Pediatr. 1991; 119 (3): 41723

12. Lee PA, Chernausek SD, Hokken-Koelega ACS, Czernichow P. International Small for Gestational Age Advisory Board Consensus Development Conference Statement: Management of Short Children Born Small for Gestational Age, April 24-October 1, 2001. Pediatrics. 2003; 111: 1253-61.

13. Kramer MS, Platt RW, Wen SW, Joseph KS, Allen A, Abrahamowicz M, Blondel B, Bréart G; for the Fetal/Infant Health Study Group of the Canadian Perinatal Surveillance System. A new and improved population-based Canadian reference for birth weight for gestational age. Pediatrics. 2001; 108 (2): e35.

14. Jobe AH, Bancalari E. Bronchopulmonary dysplasia. Am J Respir Crit Care Med. 2001; 163: 1723-29.

15. Papille LA, Burnstein J, Burnstein R, Koffler H. Incidence and evolution of subependymal and intraventricular hemorrhage: a study of infants with birthweights less than $1500 \mathrm{~g}$. J Pediatr. 1978; 92: 529-34.

16. Social Indicators minimum: Family type setting. IBGE. Available at: http://www.ibge.gov.br/home/estatistica/populacao/condicaodevida/indicadoresminimos/conceitos.shtm 
17. Bayley N. Bayley Scales of Infant Developmental. Third Edition. San Antonio, Texas: The Psychological Corporation; 2006.

18. Anderson PJ, De Luca CR, Hutchison E, Roberts G, Doyle LW and Victorian Infant Collaborative Group Underestimation of Developmental delay by the new Bayley-III Scale. Arch Pediatr Adolesc Med. 2010; 164: 352-6.

19. Stoelhorst GM, Rijken M, Martens E, van Zwieten PH Feenstra J, Zwinderman AH, Wit JM, Veen S; Leiden Follow-up Project on Prematurity. Developmental outcome at 18 and 24 months of age in very preterm children: a cohort study from 1996 to 1997 . Early Hum Dev. 2003; 72 . 83-95.

20. Wild KT, Betancourt LM, Brodsky NL, Hurt H. The effect of socioeconomic status on the language outcome of preterm infants at toddler age. Early Hum Dev. 2013; 89: 743-6.

21. Foster-Cohen SH, Friesen MD, Champion PR, Woodward LJ. High prevalence/low severity language delay in preschool children born very preterm. J Dev Behav Pediatr. 2010; 31: 658-67.

22. Van Lierde KM, Roeyers H, Boerjan S, De Groote I. Expressive and Receptive language characteristics in threeyears-old preterm children with extremely low birth weight. Folia Phoniatr Logop. 2009; 61: 296-9.

23. Janssen AJ, Nijhuis-van der Sanden MW, Akkermans RP, Oostendorp RA, Kollée LA. Influence of Behaviour and

Recebido em 4 de junho de 2014

Versão final apresentada em 22 de dezembro de 2014

Aprovado em 7 de janeiro de 2015 risk factors on motor performance in preterm infants at age 2 to 3 years. Dev Med Child Neurol. 2008; 50: 926-31.

24. Hintz SR, Kendrick DE, Vohr BR, Poole WK Higgins RD for the NICHD Neonatal Research network. Gender differences in neurodevelopmental outcomes among extremely preterm, extremely-low-birth weight infants. Acta Paediatr. 2006; 95: 1239-48

25. Silva OPV. A Importância da Família no desenvolvimento do bebê prematuro. Psicol Teor e Prát. 2002; 4: 15-24.

26. Koeppen-Schomerus G, Eley TC, Wolke D, Gringras P, Plomin R. The interaction of prematurity with genetic and environment influences on cognitive developmental twins. J Pediatr. 2000; 137: 527-33.

27. Yogman MW, Kindlon D, Earls F. Father Involvement and Cognitive/Behavioral Outcomes of Preterm Infants. J Am Acad Child Adolesc Psychiatry. 1995; 34: 58-66.

28. Procianoy RS, Koch MS, Silveira RC. Neurodevelopmental Outcome of Appropriate and Small for Gestational Age Very Low Birth Weight Infants. J Child Neurol. 2009; 24: 788-94.

29. De Jesus LC, Pappas A, Shankaran S, Li L, Das A, Bell EF, Stoll BJ, Laptook AR, Walsh MC, Hale EC, Newman NS, Bara R, Higgins RD on behalf of the Eunice Kennedy Shriver National Institute of Health and Human Development Neonatal Research Network. Outcomes of Small for Gestational Age Infants Born at $<27$ weeks gestation. J Pediatr. 2013; 163: 55-60. 